TRABAJOS DE PREHISTORIA

54, n. $^{\circ} 2,1997$, pp. $13-28$

\section{VISIBILIDAD \\ ARQUEOLÓGICA: ESCENA ARGENTINA PARA LA ARQUEOLOGÍA COMO CIENCIA DE LA SOCIEDAD}

\author{
ARCHAEOLOGICAL VISIBILITY: \\ ARGENTINE SCENE \\ FOR ARCHAEOLOGY \\ AS SOCIAL SCIENCE
}

ANA MARÍA ROCCHIETTI (*)

\section{RESUMEN}

La práctica de la arqueología está en el interior de una red social por la que los objetos arqueológicos de distinta escala se vuelven recursos culturales no renovables. La arqueología prehistórica es, en la Argentina, arqueología de las sociedades indígenas y sostiene una mediación social que desenvuelve tres dimensiones: pone en conciencia pública a esas antiguas sociedades; procura una imagen sistemática de ellas a través de los modelos teóricos y del registro arqueológico y, por último, interviene en el conservacionismo de los sitios. Este trabajo propone la investigación de la visibilidad arqueológica, tal como se plasma en el paisaje cultural de las regiones de la Argentina y la entiende como una "política de contornos o de trazos", que en la escena de la ciencia social puede adquirir carácter emancipatorio

\footnotetext{
ABSTRACT

This work examines archaeological practice inside social network where different ranges of archaeological objects become non renewable cultural resources. Indian society's archaeology supports social mediation in three dimensions: 1. putting Indian society in the public cons-

(*) Departamento de Arqueología. Escuela de Antropología. Facultad de Humanidades y Artes. Universidad Nacional de Rosario. Entre Ríos 780 - Rosario, Provincia de Santa Fe. Argentina (2000).

El artículo fue remitido en su versión final el 28-IV-97.
}

cience, 2. producing a systematic image for these societies and 3. taking part in the conservation of sites. Thus this work considers archaeological practice as having an emancipatory character within the social sciences.

Palabras clave: Teoría arqueológica. Visibilidad arqueológica. Arqueología de las sociedades indígenas. Arqueología y Sociedad.

Key words: Archaeological Theory. Archaeological visibility. Indigenous Societies' Archaeology. Archaeology and Society.

\section{INTRODUCCIÓN}

Este trabajo intenta reflexionar sobre algunos aspectos del contexto social e histórico en el que tiene lugar la producción de la arqueología prehistórica. En América Latina esta disciplina es siempre arqueología de las sociedades indígenas, ya que se considera que los restos correspondientes a los tiempos posteriores al Descubrimiento integran la arqueología del contacto hispano-indígena y la arqueología histórica. En el contexto americano, los restos recuperados por esta práctica son objetos étnicos y esta arqueología nunca es independiente del proceso de sometimiento y destrucción de esas sociedades.

El eje del trabajo habrá de ser la cuestión de la "visibilidad" arqueológica (mucho más allá de su 


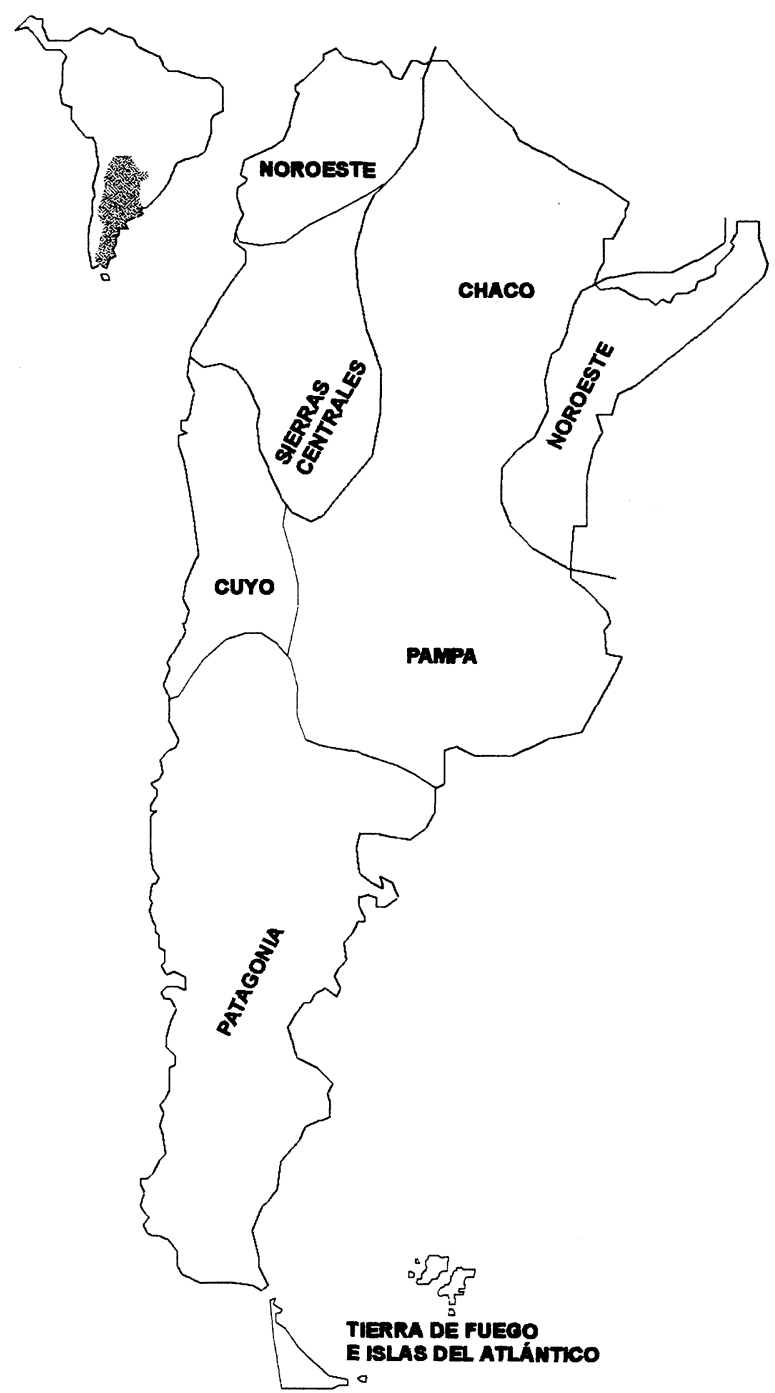

Fig. 1. Localización de las regiones de Argentina.

referente material, más directamente en su significado político) y la posibilidad de explorarla metodológicamente, considerando que ella se plasma en la identidad étnica de las regiones de la Argentina, país del extremo sur de América y con particulares condiciones de formación histórico-social (Fig. 1). Su argumento central afirma que la arqueología se define como "política de contornos", como política para otorgar visibilidad a las culturas y que -en algún punto- se cruza con la apropiación de los bienes arqueológicos, con lo cual no deja de elaborar un pasado homogéneo y europeo-céntrico. Al señalar lo que denominamos política de contornos, nos referimos específicamente a la investidura de poder que, asociada a la prácti- ca arqueológica, actualiza una cierta forma de "pasado". El ejercicio de la disciplina sumada al uso que se hace de éste -en forma colectiva y desde los aparatos del Estado- gobierna lo que se hace visible de la historia. En el caso de la Argentina y de los países latinoamericanos en general se vinculan a conflictos étnicos y de clase particulares y derivados de la especial incidencia que en ellos tuvieron tanto la Conquista como la consolidación del Estado-Nación. En razón de esta circunstancia, procuraremos analizar diferentes dimensiones y propiedades tanto del campo disciplinario en sí mismo como de la escena epistémica y social donde él se actualiza. Los argumentos pueden ser discutibles pero poseen la intención de captar el movimiento de los actores sociales comprometidos en ella.

La visibilidad arqueológica designa -aquí- el conjunto de operaciones por las cuales los arqueólogos producen contornos, esquemas, trazos, imágenes de las huellas del pasado. Ellas son parte de la tensión política que subyace a la hegemonía de la cultura europea y al contenido étnico de los sitios arqueológicos. Las sociedades vencidas durante la conquista española y portuguesa del amplio continente americano se vieron -en el caso en que sobrevivieran sin pérdida de su identidad- insertas en los Estados nacionales latinoamericanos. En el caso de la invención de la Argentina moderna (Shumway, 1992), esa historia fue subsumida dentro de una supuesta uniformidad cultural, obtenida después de la masiva inmigración de europeos mediterráneos entre fines del siglo XIX y 1923. La visibilidad arqueológica aquí considerada, en cierta medida amplifica la aplicación que ha hecho de este concepto Felipe Criado Boado (1993), quien lo ha usado para describir una tendencia social que emerge en el registro arqueológico cuando se intensifica la complejidad social. Bajo nuestro sentido puede ser entendida como toma de conciencia sobre dimensiones de la práctica arqueológica que adquiere materialidad y voluntad de "contorno" aún en el mundo contemporáneo (una sociedad evidentemente compleja).

La arqueología prehistórica se vincula a la elaboración de un pasado indio, intencionalmente no-histórico en el imaginario nacional; mediatiza la cultura india a través de la versión que de la misma proporcionan los arqueólogos. Lo hace, especialmente, desde la elaboración de clasificaciones complejas y desde la presentación científica de los restos de asentamientos y de los objetos 
contenidos en ellos. Por eso puede considerarse todo su programa como una política de la imagen: un desarrollo que culmina -necesariamenteen un conjunto abigarrado, no siempre sistematizado para el público no especialista, de íconos, diseños, matices y formas que sugieren (en museos y en publicaciones) el "remoto", "diferenciado" y -hasta cierto punto- "pasado bárbaro" de los pueblos originarios de la Argentina (1). Es decir, suponemos que la arqueología prehistórica -por lo menos en la Argentina- no puede dejar de constituir una política que selecciona aquellas dimensiones del pasado que habrán de hacerse visibles, tanto en la comunicación académica cuanto en la difusión que de sus temas hacen los medios masivos de comunicación.

Vamos a considerar, en primer término, las características de la arqueología prehistórica desde el lugar de la convergencia de argumentos pluridisciplinarios que integran su cuerpo de saberes. En segundo término, examinaremos el vínculo entre arqueología y visualidad, entre arqueología y ciencia social y, por fin, entre arqueología y reforma social.

Estos temas pueden aportar puntos de vista para criticar el rol de esta disciplina, para advertir cómo puede ser en el futuro y, fundamentalmente, para debatirlo a la luz de las condiciones en que se ejerce en países no europeos. En la interacción entre ciencia y sociedad, importan no sólo la forma y medida en que se construye el conocimiento sino también las características de su uso social y sus consecuencias inmediatas o lejanas, voluntariamente planificadas o no, libertarias u opresoras. Hechos, conceptos, excavaciones y laboratorio no valen por sí mismos en esta perspectiva: se amplifican con destino incierto en los vínculos que vamos a examinar.

\section{ARQUEOLOGÍA Y CONVERGENCIA DE ARGUMENTOS}

La práctica de la arqueología de las sociedades indígenas de la Argentina puede ser reflexionada a partir de tres proposiciones conectadas íntimamente. La primera sostiene que el registro arqueológico pertenece tanto a la esfera de la producción simbólica como a la de la producción sistemática (o metodológico-objetiva), y -por eso mismo-es,

(1) Cómo esas imágenes devienen representación social, constituye una investigación cuya envergadura se encuentra fuera del alcance de este trabajo. a la vez, correlato de una subjetividad productora y de un proceso de construcción de subjetividad en los arqueólogos, en los especialistas vinculados a ellos y en el público general de su literatura y de sus materiales de divulgación. La segunda lleva la práctica de la arqueología al interior de una red social (de especialistas y de no especialistas); la misma consiste tanto en comunicación como en adhesión axiológica a ideas y a imaginarios colectivos. Constata que los objetos arqueológicos de distinta escala (desde sitios completos hasta objetos transitoria o completamente descontextualizados) se vuelven recursos culturales no renovables que comprometen a distintos sectores sociales y a variadas formas de acción, interés y compromiso, generalmente ligadas a su condición patrimonial. Esta temática concentra, desde hace varios años, el interés de los arqueólogos de la Argentina.

Los aspectos de la práctica arqueológica comprometidos en estas afirmaciones se vuelven importantes -o por lo menos, dignos de atención-en un momento de intensa transformación de los esquemas teóricos porque comenzamos a darnos cuenta de las consecuencias que tiene otorgar primacía al significante. Entre ellas, las más cruciales son el desinterés por la multiplicidad de sentidos que puede provocar en el público la aparente unicidad sistemática de las palabras de los textos científicos, la desatención sobre los ecos ideológicos que esconde la presentación textual y visual de los hechos arqueológicos y de los conceptos cobertores a contramano de la aparente neutralidad positivista y la ausencia de crítica cultural sobre el producto visible y manifiesto de un siglo de ejercicio de arqueología prehistórica en la Argentina. En síntesis, de la carencia de crítica (2) sobre las representaciones que evocan las palabras en la arqueología argentina.

De lo que se trata, en realidad, es de dar forma a la responsabilidad por aquellas dimensiones del saber arqueológico que antes se ponían por fuera de la práctica, derivándolas a otras instituciones o competencias profesionales. Este es el punto en que coinciden el estilo de investigación y el compromiso social y político para evaluar las dimensiones documentales, científicas y gerenciales de los sitios arqueológicos.

En la Argentina, las comunidades indígenas tienen una forma de presencia cultural mínima, en parte por su baja densidad demográfica pero tam-

(2) Crítica, en sentido kantiano, como "conocimiento"; crítica, en sentido marxista clásico, como "desenmascaramiento". 
bién -y especialmente- porque la cultura pública (3) argentina se define como europea. Asimismo, la diversidad de la historia cultural en las regiones (4) ha plasmado un perfil a veces permeable (5) y a veces, no (6), a integrar el componente aborígen al imaginario nacional. En parte, esto explica la debilidad de la cobertura legal de protección y de administración de los bienes culturales derivados de los restos de las antiguas sociedades indias.

En la Argentina, la arqueología que se denomina "prehistórica" pone en foco a las sociedades indígenas desaparecidas a través del proceso por el cual los que fueron sus asentamientos se transformaron en sitios arqueológicos. Estas sociedades son exteriores desde el punto de vista de que sus núcleos institucionales y políticos no participan de la entidad histórica que viera surgir el siglo XIX bajo el nombre de "Nación" (Estado-Nación). En el imaginario nacional, las sociedades indias exponen una forma de conciencia histórica que es considerada como pre-moderna y anterior a la Nación misma. Es en su exterioridad donde se vuelven objeto de representación y donde se les asocia un sistema de valores: son sociedades "extrañas", "exóticas" y por fuera del mundo "civilizado"; muchas de ellas se extinguieron antes de la llegada de los europeos y otras fueron sucumbiendo a la conquista entre los siglos XV y XX. Sobre todo aquéllas que fueron exterminadas durante la penetración en el Desierto pampeano y en el Chaco Austral por el Estado Nacional son -todavía hoy-consideradas un obstáculo al progreso y a la modernización del país.

(3) "Cultura pública" designa, en este trabajo, las dimensiones expuestas y visibles de los comportamientos sociales que merecen una descripción de significados y de símbolos específica, sobre todo por sus implicaciones en la historia del país y con la antropología de sus tradiciones culturales. La cultura pública es una parte del "sentido común" que enlaza - si bien de manera asimétrica- la dialéctica de las ideologías entre las clases sociales en la Argentina y posee un carácter sistemático en la medida en que es la escuela el factor más importante en su reproducción.

(4) Sumariamente, ellas son el Noroeste argentino, las Sierras Centrales, Cuyo, el Nordeste (Litoral o Mesopotamia), Chaco, Pampa, Patagonia, Tierra del Fuego e Islas del Atlántico Sur (Malvinas, Georgias, Sandwich y Orcadas del Sur).

(5) En la Argentina, tanto el populismo como el nacionalismo integran el pasado aborigen como parte del "pueblo", en el primer caso, como parte de las raíces de la nacionalidad en el otro. Sin embargo, ambas corrientes políticas no son equivalentes en el tratamiento de la cuestión. Los matices escapan al objetivo de este trabajo.

(6) Es el caso del liberalismo de la generación del '80, que no sólo realizó la Conquista del Desierto pampeano-nordpatagónico, eliminando físicamente a los indios, sino que procuró extirparlos del relato de la Historia Nacional.
Las sociedades antiguas, en todas sus variantes, ponen en vigencia un mundo dual, basado en la antinomia bárbaro-civilizado, simple-complejo, inferior-superior, mágico-racional (cfr. Colombres, 1988: 15). Por otra parte, sus formaciones económico-sociales sugieren un mundo sin historia, anterior o paralelo a la escritura y a las instituciones europeas, semejante al que describe el título de la obra de Eric Wolf, Europa y los pueblos sin Historia.

Pero si las sociedades indias son tratadas como un tipo social único (no europeo, no civilizado, no histórico) es porque su posición axiológica es correlativa de un tratamiento político (también unitario) que pasa por alto su heterogeneidad étnica (ya que todo lo indio no puede ser adjudicado a un solo bloque histórico) pero también el de la heterogeneidad social, política y étnica de la sociedad nacional.

Coherentemente con este esquema axiológico, la arqueología prehistórica abarca la historia preeuropea y su objeto científico es representado como una entidad desconectada tanto de la situación actual de los indígenas en territorio argentino (en especial, en relación con sus derechos sobre los restos arqueológicos), como de la destribalización violenta que sufrieran en su confrontación con los europeos.

Deseamos destacar que, independientemente de su calidad académica y técnica, la arqueología prehistórica (en las condiciones de producción americanas) se encuentra en una situación histórica particular: la Nación aparece como superadora de las diferencias culturales porque intenta ser un todo uniforme y homogéneo. Lo que sobrevive del mundo indio posee el lugar jurídico de la ciudadanía y no de las minorías étnicas (vivientes o extinguidas); el perfil de la Nación es blanco y europeo, el componente indígena fue, y es, sometido a silencio etnográfico.

La arqueología prehistórica, entonces, configura su objeto como constructo científico de carácter presuntamente neutral (7) pero en lo profundo su objeto es de naturaleza tanto científica como política. Esta situación es su determinante más conspicuo. En ella tensan tres tradiciones semióticas (tres tradiciones de producción de sentido y de selección de significantes) diferentes: la de las ciencias naturales, la de las ciencias socia-

(7) La neutralidad en el orden científico es, según nuestro punto de vista, equivalente a la abstracción sociológica de la "ciudadanía" en el orden público. 
les y la de la historia. Cada una de ellas le aportan problemas, teorías y desarrollos lógicos que, habiéndose constituido históricamente, han terminado por adquirir centralidad de enfoque y competencia específica sintomatizadas en comunidades de lenguaje y profesionalidad.

La principal actividad heredada de las ciencias naturales es la búsqueda de la verdad objetiva, aquélla que escapa a la determinación del proceso social y político y que se entiende como autónoma de cualquier determinación histórica e ideológica. $\mathrm{Su}$ estructura de problemas se deriva del modelo organizador de la ciencia en un momento dado (el "paradigma"). Las ciencias sociales y humanas participan de esta línea argumental, pero una parte de ella interroga -desde sus orígenes como territorio de saber- hasta qué punto existe una separación neta entre el objeto y el sujeto en el conocimiento, en qué medida la heurística se deriva del sujeto, debatiendo la naturaleza de un trabajo que oscila entre el descubrimiento de las leyes de lo real y la espontaneidad como principio de realidad.

La opción entre una forma y otra de abordar los fenómenos sociales y naturales se encuentra en la esfera de la competencia entre tres orientaciones que puede tomar la investigación en cualquier campo (Habermas, 1971): el control técnico conducido por el conocimiento nomológico cuya búsqueda excluyente es la de las leyes, estructuras, tendencias o recurrencias en la sociedad o en la naturaleza; la comprensión de sí (particularmente la de la sociedad y la de la condición humana) a través de un acceso dialógico y concebido como "entrada en otra tradición" (Giddens, 1987) y, por último, la emancipación respecto de toda forma de opresión. Si las primeras pertenecen al ámbito del conocimiento y de la técnica, la última posee carácter libertario, individual y colectivo.

La orientación hacia la ciencia social tiende a privilegiar el logro de la comprensión, aunque posee una dimensión volcada a la ingeniería social. Aquí es donde la arqueología prehistórica encontraría su rol de refuerzo o de transformación de la cultura pública. Como ciencia social, y en tanto ingeniería aplicada a la sociedad, habría de volverse constructora de espacios de interacción y lucha social, intentando diseñar la sociedad del futuro, incidiendo en la configuración de imaginarios colectivos (Castoriadis, 1990), aprehendiendo la particular manera en que los oprimidos dan cuenta de su situación y de su historia y procurando verificarla en los signos que aparecen en el proceso social. En esta dirección no sólo describe, comprende y explica; también señala, concientiza, evoca (8). Asimismo, el control social inherente a esta dimensión performativa también es real. El contorno causal que se da al pasado, la exposición de cómo éste se ha desarrollado, deviene un contorno político.

Al poner a luz los objetos del pasado (con las imágenes y palabras que los museos y los libros reproducen y escenifican) dando a éste por definitivamente terminado; al aprehenderlo como una totalidad lejana y exótica, prueba de una historia que no puede ni debe ser repetida, al constituirlo como apartados especiales -y residuales- de $\mathrm{Cu}$ rricula educativos que lo exhiben como una parte mínima y anecdótica de la historiografía del país, muestra su carácter de efectivo control social, mantiene en un estado de baja organización corporativa a las comunidades y refuerza para la mayoría de la población su imaginario europeo (9).

Lo que sostenemos es que el saber emancipatorio ayuda a comprender cualquier forma de dominación, a encontrar las determinaciones históricas del presente, a desconstruir imágenes, prejuicios y núcleos erróneos, a concientizar sobre las razones de las situaciones injustas y a trascender su función autoritaria.

La mediación de estos campos semánticos demarca el territorio de las metodologías, es decir, de los instrumentos de análisis que se encuentran a disposición de la arqueología indígena. Por un lado, se ligan a una estrategia que consiste en "co-

(8) La arqueología prehistórica, en la Argentina, sería directamente funcional a lo que queda de las comunidades indígenas en su proyecto de recuperación de identidad étnica. Pero no solamente a ellas, en la medida en que el esclarecimiento de su condición de oprimidas exige el examen de toda la historia nacional y del carácter de sus actores sociales.

(9) La envergadura de ese imaginario no resulta solamente de la condición de pensar los propios orígenes demográficos y sociológicos, sino de oponer la identidad propia a una identidad aborigen con la que la mayoría no se siente comprometida. Esto tiene dos efectos: por una parte, desliga a la población que cuenta con ancestros indígenas de su involucramiento con los "compatriotas" que a duras penas sobreviven en comunidad o que han emigrado de ellas hace una o dos generaciones; por otra, hace que los descendientes de la gran inmigración española e italiana no se sientan para nada involucrados con esta temática, a no ser en relación con la invención de una nueva tradición gauchesca (los nietos de los "gringos" de la región pampeana, que cultivan las artes y vestimentas camperas, especialmente las ecuestres, a fin de rodearse de una prosapia patricia ligada a la tierra y a las "raíces" adquiridas recientemente) o con un sentimiento de admiración reconocida a las reliquias de un país que podría ser más antiguo que lo que imaginaban. 
nocer desde afuera" (tradición de las ciencias naturales y de una versión de la sociología) y, por otro, a la que se funda un "conocer desde adentro", próximo a la práctica de discurso que se basa en desenvolver una hermenéutica de los acontecimientos históricos y sociales. Optar por una u otra metodología incide en la arquitectura de los diseños de investigación. Es así que desde hace media década (lapso en que se difundió un contra-paradigma al enfoque sistémico entre los arqueólogos argentinos) se contraponen como términos de adhesiones alternativas - pero no excluyentes- el procesualismo y el post-procesualismo.

El procesualismo (10) representa una búsqueda de la neutralidad, de la verdad "objetiva" y la confianza en la autoridad del modelo organizador consensuado, paradigmático. El post-procesualismo (11) -heterogéneo en posiciones teóricoprácticas- pone en evidencia la crisis de historicidad venida a luz en los paradigmas científicos. En especial la que deriva de la impugnación articulada por la física de los estados caóticos (cfr. Prigogine y Stengers, 1983) y por las filosofías del sujeto al absolutismo teórico, sostenido en la autonomía de la verdad y en la esperanza de encontrar leyes y tendencias en la realidad. El procesualismo imperó como modelo constructivo en los $70 \mathrm{y}$, más tarde, fue cediendo paso a una variedad de enfoques que además empezaron a considerar el entrecruzamiento entre arte, ciencia y saberes populares en un marco de anarco-epistemologías (Feyerabend, 1990 y Bunge, 1994). Éstas tienden a disolver la autoridad científica como tal e introducen problemas referidos al poder, a la sobredeterminación cultural sobre las acciones humanas y a la dimensión cotidiana de los objetos recuperados arqueológicamente (Hodder, 1988; Alcina Franch, 1989; Patterson, 1989).

El procesualismo adhiere a metodologías explicativas, privilegiando los modelos funcionales y la obtención de una confirmación intersubjetiva y consistente. Sin embargo, el discurso explicativo no es ajeno al campo post-procesual en sus versiones estructural, generativa y dialéctica. De todas maneras el interés principal de este último apunta a explorar la comprensión contextual y semiótica.

(10) El procesualismo comprende las metodologías sistémica, ecológico-funcional, conductista y la arqueología espacial.

(11) El post-procesualismo se delimita actualmente como arqueología estructuralista, arqueología simbólica, arqueología neo-marxista, arqueología crítica, arqueología feminista y arqueología "marginal".
Se puede describir la explicación como una estructura teórica en las que las categorías se implican, configurando un conjunto sistemático de leyes (o, por lo menos, enunciados generales) y principios objetivos, relativo al lenguaje en que se formula y desde el cual consolida una epistemología normativa (Borel, 1981). Pero es posible, también y desde otra perspectiva, tomarla como un género argumental; como un estilo en el seno de una tradición alternativa: la que toma al discurso como un objeto-signo que no puede ser sino relativo a quien lo enuncia, polisémico y clasificador.

Éste último aspecto -su carácter clasificadores importante, puesto que la arqueología indígena posee un núcleo de práctica fundante en la asignación ubicua de las propiedades de los objetos que recupera (sean objetos plenamente culturales, sean objetos biológicos como los esqueletos o los derivados de la dieta, sean objetos quimiogénicos o biogénicos como las huellas de los procesos tafonómicos, etc.) a categorías discriminadoras. Por este trabajo procura, asimismo, dar cuenta de las sucesivas y múltiples transformaciones de los fenómenos arqueológicos. Su resultante es el registro arqueológico, el cual sintetiza acumulativamente la combinación de objetos arqueológicos con el inventario de sus propiedades (Austral y Rocchietti, 1990).

Las metodologías señaladas dan uno u otro lugar al registro arqueológico en forma consistente con sus presupuestos teóricos: los procesualistas lo ven como un correlato de la construcción cognitiva, mientras que algunas tendencias post-procesualistas lo consideran derivado de la construcción discursiva. Desde aquella perspectiva el registro arqueológico constituye un fósil objeto que documenta el pasado (y que existe en sí y por sí) y desde la segunda un texto (Patrick, 1983), es decir, un objeto-discurso elaborado por la capacidad de "lectura" proyectada por el investigador sobre los fenómenos arqueológicos (derivada en gran medida de la potencialidad técnica y de los marcos teóricos de cada época). En tanto fósil, el registro arqueológico es un objeto de conocimiento que habrá de conducir a trazar una historia "fósil" de las sociedades indias. En tanto texto, tiene que ver con los actos de registro (y sus interferencias), con la imagen de una experiencia en la que la forma de objetividad es correlato de una forma de subjetividad que se desenvuelve en los términos de una producción simbólica.

La arqueología de las dos últimas décadas ha

T. P., 54, n. ${ }^{\circ} 2,1997$ 
articulado prescripciones bastante precisas para conducir la práctica del registro. Consisten en hacer explícito el diseño de investigación, privilegiar la investigación regional más que la de sitio, interpretar en términos socio-económicos los datos arqueológicos, extender el pasado arqueológico al presente, tomar conciencia del rol social de la arqueología y esforzarse por dotar de autonomía al campo de la disciplina respecto de la historia, de la antropología y de la ecología cultural (Glock, 1985: 464).

Si bien -y de acuerdo con lo expuesto- la tendencia académica consagra una tradición de conocimiento y práctica considerada "sistemática", existe paralelamente una evocación de arte, de artesanía, de industria cultural y de coleccionismo que compone un compromiso lateral pero intenso (Rocchietti, 1991). No se trata solamente de que la arqueología coexista con ellas sino de reconocer que también involucra una lógica implícita -que se despliega desde aquéllas- que consiste en re-elaborar, re-significar, inventariar y mostrar. Habitualmente esa lógica es considerada expresamente como para-sistemática y auxiliar, pero en ese ámbito la arqueología adquiere categorías nuevas para la percepción. Ellas son necesarias una vez que se toma conciencia acerca de que los asentamientos indígenas y sus contenidos son recursos culturales no renovables, en relación con los cuales el proceso de investigación contribuye a que sean disfrutados y valorados por las generaciones del futuro. La arqueología resulta, así, una estrategia para descubrir una parte del paisaje cultural regional: la que está integrada por la base social, económica e ideológica de las sociedades antiguas en su red ecológica. Ella se proyecta en el presente como una suerte de matriz que impregna la región y como aporte a la identidad de las áreas geográficas porque se articula con la historia local de distintas maneras (12). Una parte del paisaje cultural es el paisaje tecnológico (Foley, 1981) y no equivale a él en su totalidad, de modo tal que conviene segregarlo como componente particular de la percepción regional, sobre todo

(12) Generalmente cuando es mayor la envergadura de los restos arqueológicos de procedencia indígena porque tienen la forma de recintos, fortalezas o pucaras, campos de cultivo o andenes, hidráulica, templos o construcciones de defensa o enterramiento de los muertos con complejidad y esplendor, mayor es el compromiso con ese pasado. En la Argentina, es el caso de la región Noroeste que despliega toda la magnitud de las culturas andinas aunque en forma de periferia a la llamada por los arqueólogos Area Andina Meridional. porque el acceso a las instalaciones indias (habitaciones, campamentos, talleres, sitios de caza, territorios, etc.) se hace por la visibilidad de los equipos tecnológicos que fabricaron y usaron. Se documenta en los sitios arqueológicos como objetos líticos, cerámicos, óseos y metálicos, arquitecturas de recintos, etc.

El paisaje cultural es una propiedad general de la región; el paisaje tecnológico encarna en la base arqueológica y es antecedente histórico o "etapa" en la historia tecnológica regional, la que habrá de articular, sin duda, componentes tecno-urbanos y tecno-rurales en una secuencia que le es específica. El paisaje tecnológico se cruza con el coleccionismo, con el arte y la artesanía, porque les ofrece un universo de objetos que son directamente reconocibles, que se pueden reproducir o copiar, que se re-elaboran y se coleccionan.

Paisaje cultural y paisaje tecnológico antiguos tornan la evidencia de la variación de los conjuntos arqueológicos y de las actividades que las poblaciones indias realizaban dentro y fuera de los asentamientos, un objeto de preservación y gerencia. Exigen de la práctica arqueológica una conexión profunda con la "forma regional" (Sullivan, 1988) tanto desde la perspectiva de la historia como desde las decisiones de conservación, comunicación e incidencia social de los recursos arqueológicos. Al igual que las otras disciplinas que tienen por objeto los asuntos humanos, la arqueología participa de la configuración constitutiva expresada en los pares foucaultianos función/norma, conflicto/regla y sentido/sistema (Foucault, 1981). Bajo el primero la interpretación de la sociedad se efectúa acentuando sus características de totalidad funcional (orgánica y/o sistémica). Bajo el segundo se enfatiza que los órdenes sociales están fundados en distintas formas de apropiación económica, en la contradicción y en la lucha; desde el tercero se sostiene una versión fundada en los niveles de significación del lenguaje y de todos los universos simbólicos de la acción social.

Desde nuestra perspectiva, la visibilidad arqueológica se actualiza en tres dimensiones: en el registro de sitio, en el sostén de sitio y en la intervención de sitio.

El registro es la dimensión que se encuentra en la recuperación sistemática y en la procura de significado para los procesos de formación y de transformación de sitio. El sostén de sitio se configura a partir de la asistencia técnica que es necesaria para preservarlo pero sin interferir con la histo- 
ria física y política del sitio mismo. Esta dimensión consiste, más bien, en esas estrategias tan comunes en la Argentina de "proteger sin tocar" los yacimientos. El espectro de posibilidades de las mismas van desde quitarlos a la curiosidad pública, no denunciando sino académicamente su existencia, hasta las gestiones públicas para su eco-conservación y las campañas para formar conciencia ciudadana sobre su preservación como patrimonio cultural. La intervención de sitio reúne todas las operaciones físico-químicas, arquitecturales, culturales y políticas que desenvuelven la preservación y la comunicación social de la arqueología prehistórica.

En la Argentina, en relación con la inestabilidad de las políticas científicas estatales, solamente un porcentaje reducido de la totalidad (indeterminada) de sitios arqueológicos es puesto en situación de registro; a su vez, sólo un pequeño número de ellos es puesto bajo actividades mínimas de sostén y, por cierto, la intervención técnica y política está reservada a los casos de interés excepcional (sea por su envergadura monumental, sea por tratarse de localidades arqueológicas que reciben atención turística, sea porque pueden volverse escuelas de campo para arqueólogos).

Registro, sostén e intervención son dimensiones siempre "inacabadas" en la medida en que las metodologías varían en el tiempo, expresando el potencial histórico de la arqueología en cada época y para cada generación de investigadores que se encuentran en la dirección de concretarlas. Asimismo, son dimensiones "interminables" ya que nunca se agotarían como objetos científicos, existiendo siempre la oportunidad de descubrir o implementar nuevas formas de tratamiento tanto de la información como de los sitios arqueológicos.

En la dimensión del registro de sitio, la problemática crucial gira en torno a la materialidad de los observables; es decir, en qué medida y con qué fiabilidad las propiedades físicas, bióticas y documentales se vuelven información y se mantienen en los procesos aceptados de validación. Las otras dos dimensiones están centradas en la transformación que conduce -inexorablemente- a la desaparición de los yacimientos, tanto en los vectores de perturbación ecosistémica como por la acción humana. Ella evoca la dialéctica interior a lo observable que se vuelve no observable y que suele traducirse en una estimación de la estabilidad de los sitios.

La visibilidad arqueológica, entonces, es poli- morfa y -por lo tanto- polisémica y no puede dejar de estar integrada al paisaje cultural.

La adherencia de los fenómenos arqueológicos a aquél se verifica en la impronta que dejaran las comunidades indias en la región a través de los restos de lo que fuera su base social y económica y su ideología. Al no poderse separar estos conjuntos de su red ecológica, ofrecen un perfil de reconocimiento a la región: sea porque los monumentos y ruinas se imponen en el paisaje, sea porque los motivos decorativos de la cerámica y textiles arqueológicos se reproducen y reelaboran en las artesanías populares y comerciales, sea porque piezas auténticas o falsas forman parte del adorno de edificios públicos y privados, el paisaje cultural adquiere identidad en función de esa impronta.

En la Argentina, existe un gradiente notable en la articulación de esa impronta: mientras la Argentina andina exhibe algo de la visibilidad arqueológica vinculada al mundo indígena (sobre todo por el impacto notorio de las altas culturas de la sierra peruana, del altiplano boliviano y de la puna chilena) de tal modo que ella se percibe en la artesanía y en la iconografía turística en forma de dibujos que reproducen los diseños de las cerámicas o de los textiles o de fotografías que muestran sitios arqueológicos notables (la ciudad arqueológica de Tastil, el pucará de Tilcara); en la Argentina pampeana ella se diluye inexorablemente en la hegemonía dada a la cultura europea.

Lo cierto es que las tradiciones indias presentes en los paisajes culturales contemporáneos desafían el paradigma de la cultura europea porque representan una fractura visual y de sentido en el paisaje sincrético contemporáneo. El paisaje cultural pertenece al régimen de lo visible porque combina de una manera específica las tradiciones étnicas que han interactuado en el pasado y que aún lo hacen en el imaginario colectivo.

En la Argentina -y en toda América- la arqueología se desenvuelve -o debiera- en el plano de una memoria étnica porque no puede dejar de subrayar diacríticamente la visualidad orgánica del paisaje cultural y actuar en la dirección de investigar su identidad. La práctica arqueológica no sólo exhuma lo que queda visible del pasado indio, sino que lo adhiere a un tipo de visibilidad -por así decir- crítica: lo que las historias oficiales reducen a una mínima parte porque la sociedad se imagina blanca y europea, es sacado de la confusión y del olvido por la arqueología en el plano de ruptura de lo visible. 
Los arqueólogos irrumpen en la imaginería de la sociedad mass-mediática con formas disruptivas que van a parar a los museos, pero que obligan al reconocimiento de la existencia del silencio etnográfico. Sin ese conjunto de objetos y diseños exóticos para el común de la gente no habría necesidad de ir más allá del tiempo y de la sociedad que inauguró la Colonia o, más tarde, la Nación.

Una parte del diseño de la investigación arqueológica consiste en representación, esquematización, figuración o trazo. Existe un aspecto del trabajo arqueológico (que, por supuesto, no lo agota) por el cual se construyen imágenes (registros, códigos, esquemas de sitio, bocetos de intervención, etc.). Su dilema más importante es establecer los contornos de los fenómenos arqueológicos y de la realidad histórica a la que ellos pertenecieron. De allí que la visibilidad arqueológica se vuelva política de trazo gráfico, fotográfico, fílmico.

La investigación de los contornos en arqueología es inseparable de una política de trazo desde varios puntos de vista.

Mirado desde cierto ángulo, el contorno no existe como tal. Es, más bien, una frontera entre las cosas (Moles, 1991), zonas difusas entre los objetos y los datos (como las que existen entre sitio y no-sitio, entre diseño tecnológico y diseño artístico). En este sentido, el contexto mismo se vuelve inconmensurable: ¿cómo obtener criterios para considerarlo alcanzado y acabado?; ¿hasta dónde se extiende -razonablemente-aquéllo que se designa como contextual?

Una política de trazo genera una programática constructiva que determina la escala de los hechos arqueológicos. Una política de trazo es distinta a una política de texto (Austral y Rocchietti, 1990): la escritura y el montaje arqueológicos que pusieran en evidencia la asimetría de la apropiación del patrimonio arqueológico o, por el contrario, la ocultaran. Una política de trazo se vincula al potencial de la arqueología para volver a la información contornos o bosquejos, para suscitar una exploración del objeto científico (los observables de ese "yacer ahî" que son, en definitiva, los sitios arqueológicos) y dar lugar a una economía de lenguaje particular.

Este proceso es polimorfo en la medida en que va desde el registro fílmico al rastreo microscópico de huellas de uso y desde el diagrama abstracto a la reproducción figurativa, desde la imagen analógica a la imagen digital. Y, también, multiplica- dor de sentido por dos razones: porque es producido por una subjetividad epistémica y porque genera nuevas formas de subjetividad en los receptores de la política de trazo. Un ejemplo de ello se puede encontrar en la manera en que la arqueología trata con los cambios tecnológicos. Éstos constituyen una clase de cambio histórico y ofrecen, generalmente, una escala de la sociedad porque no dejan de ser juzgados en términos de complejidad y naturaleza de la transformación social comprometida. La impregnación de la vida por la tecnología suele ser tal-independientemente de la época-que su paisaje pasa desapercibido para los que la viven (cfr. Mercier, 1986). Pero la arqueología los presenta, ante la subjetividad etnocéntrica, en el tiempo largo y en el carácter resolutivo de la supervivencia, exhibiendo lo que cotidianamente es imperceptible.

Así se articulan en su dimensión histórica real la transformación de los diseños de piedra, la domesticación de plantas, la manipulación de las hogueras, el tendido de muros, etc.

El mundo conocido es develado en su entramado histórico, en la manera en que sus conquistas técnicas o ideológicas se fueron enlazando en la esfera de la experiencia histórica. La percepción "aplanada" de las formas y de las funciones de las herramientas y artefactos que nos rodean en la actualidad puede llegar a ser transformada por el reconocimiento de cómo históricamente se superpusieron.

Al pasar a otros materiales significantes o al comprometerse con los contornos (en el caso argentino o latinoamericano con los contornos de las sociedades indias) aparece más claro el lugar actual de la arqueología: el de la tensión dialéctica entre su singularidad de campo (lo que es decir, de trabajo, de textos y de visualidad) y su conectividad, es decir, la intercomunicación con la antropología y la historia.

\section{ARQUEOLOGÍA Y ESCENA DE LA CIENCIA SOCIAL}

Si la visualidad es un programa constructivo, entonces surgen algunos interrogantes:

- ¿cómo se demarcan territorios de procedimiento y de eficiencia en un programa que busca intencionadamente la visualidad?;

- ¿cómo conectar el telón de fondo de la historia social (representada por el paisaje cultural que 
posee una identidad visual reconocible y en la $\mathrm{Ar}$ gentina en unos casos en mayor grado que en otros) con las microculturas teóricas y académicas?;

- ¿cómo organizar la discursividad arqueológica y cómo caracterizar su devenir en hecho social cuando se está en el interior de la práctica?;

- ¿cómo obligar a repensar el vínculo técnica/ teoría/ realidad en la dimensión del uso de la continuidad mediática (actualmente digitalizada y con vastas posibilidades de montaje y expansión informática)?;

- ¿de qué modo los procedimientos se imponen sobre los resultados de la investigación?;

- ¿cómo responder a los desafíos éticos (re-enterramiento de restos arqueológicos correspondientes a la historia de comunidades indígenas, cuyos descendientes están en condiciones jurídicas de reclamarlos) y estéticos (el despliegue de la visualidad arqueológica en contraste con el paradigma de la visualidad planetaria del siglo XX)?;

En principio los procedimientos ligados al proceso visual requieren de saberes tradicionales (dibujar, esquematizar) tanto como de nuevos (cámara y montaje, computación y medios de almacenaje digital). Apuntan a generar información pero también a comunicarla y, por lo tanto, exigen una economía de lenguaje nueva: ni la hiperfigurativa del registro de campo en bruto ni la sintética del clip. Exigen intergéneros (García Canclini, 1991: 77). Esto significa combinar textos o escrituras de la comunicación científica habitual, guiones, fundidos de imágenes y "travellings", sonidos digitales o voces humanas, escenografías de teatro en los museos, gráfica de publicidad y exposición mural, etc.

Algunos exponentes serán más eficaces que otros. Algunos profundizarán en la documentación y en la producción de datos adecuados para modelizar. Otros tendrán impacto en la comunidad a través de los media y generarán ya no lectores científicos sino espectadores y tele-adictos.

Es más difícil anticipar cómo habrá de juzgarse esta eficiencia. Pero al buscar intencionadamente una extensión mass-mediática de los hechos arqueológicos o una comunicación que destaca lo visual, se vuelve evidente que la imbricación entre la historia social (la del pasado y la que se desenvuelve ante nosotros) y las microculturas teóricas tendrá consecuencias más profundas puesto que insertar la tradición india en el continuo de la historia social y política del paisaje cultural obliga a un examen crítico de la sociedad y de la cultura.
Los hechos arqueológicos -contrariamente a lo que pudiera pensarse- no son independientes del destino que sufrieran las comunidades indígenas dentro del Estado-Nación en la Argentina. Allí, la situación del objeto científico es la de una apropiación asimétrica de sus restos por parte de la sociedad que se hiciera hegemónica a lo largo de los siglos. La discursividad arqueológica no puede dejar de señalarla porque de una manera o de otra ella deviene del proceso que venció a esas comunidades expropiándoles, también, el control sobre los restos arqueológicos.

Un hecho que pone de relieve lo crítico de esa toma de conciencia es el debate en torno a los reclamos de devolución de restos para su posterior re-enterramiento por parte de asociaciones indígenas en América y en Australia (cfr. Zimmerman, 1989).

La posibilidad de re-enterramiento no sólo destaca la no-visibilidad virtual, como consecuencia de la tensión política que le subyace, sino el control cultural sobre los indios (Bonfil, 1991: 81) ejercido en el pasado y prolongado en el presente por la apropiación asimétrica de los restos. El reenterramiento retira de la visibilidad los objetos arqueológicos poniendo en evidencia una parte de su naturaleza política.

Pero existe, también, otra tensión básica en la presentación de la visualidad de lo indio a través de los objetos arqueológicos: la que impone el esfuerzo por imponer una visualidad sobre otra. El espectador habrá de necesitar para gran parte de lo que ve un aporte de significados (esa urgencia que expresan las preguntas ¿qué es?, ¿para qué sirvió?, ¿qué significaba?, ¿cuándo se fabricó?). La dialéctica entre lo que se ve y lo que se cree ver intenta resolverse sometiendo una visibilidad (la india) a otra (la socializada en torno a las formas y funciones de los objetos en la cultura europea) y procurándole una toma de sentido que la reduzca a los parámetros no perturbadores del propio mundo cultural. La visibilidad recuperada por la arqueología desafía cánones históricamente impuestos, los que confrontan criterios estéticos radicalmente distintos.

La actual amplificación técnica (microscopios electrónicos, rayos $\mathrm{X}$, películas infrarrojas, video, computadoras, etc.) obliga a volver a pensar el nexo entre Técnica/Teoría y Realidad. Hasta tal punto la imposición de los nuevos media ha influido en los procedimientos de registro y comprensión de lo real que se puede afirmar que las inno- 
vaciones técnicas son "transversales". Atraviesan todas las instancias de lo real y, en especial, la producción científica (Manzini, 1991): de allí la necesidad de rever los contornos de las cosas y de examinar las microculturas teóricas (las que se corresponden a sectores de teoría, equipos de trabajo y metodologías de investigación).

Necesariamente los procedimientos se imponen sobre los resultados de la investigación. Sus límites son los de las mencionadas microculturas; su potencial depende - en gran medida- de los factores de estima que suelen pesar sobre los investigadores. El prestigio de los modelos funcionales cibernéticos para entender a las sociedades indias fue hegemónico en los ' 80 . En aquélla época era natural sostener que los modelos y categorías basados en el comportamiento de los sistemas informáticos describían adecuadamente el funcionamiento de esas sociedades y existía una confianza real en que ellos permitían predecir su registro arqueológico. De su cuestionamiento actual surgen metodologías divergentes y heterogéneas que seguramente habrán de ser puestas en duda cuando agoten su itinerario teórico y práctico.

Sin embargo, la energía puesta en la exploración de procedimientos es la que vuelve a la arqueología un taller experimental, especialmente ahora que tiene lugar un período de discontinuidad epistemológica, de evolución hacia otros aparatos normativos (cfr. Vicent, 1991). Esto obliga a pensar el vínculo entre arqueología y sociedad.

Hoy existe una demanda social creciente hacia el conocimiento, originada en instituciones públicas y en las grandes burocracias privadas. En lo que respecta a la ciencia social, esa demanda la encuentra como un campo científico poco estructurado y en productividad decreciente (Fanfani, 1991). Existe un nexo directo entre arqueología y sociedad y éste surge con claridad en el marco regional: los restos arqueológicos son recursos culturales no renovables y su tratamiento crea un área de gestión y de intervención que define público, objetivos y medios de comunicación.

En ese carácter de recursos, los restos arqueológicos empiezan a vincularse a la superposición de tecnologías regionales (antiguas y modernas, rurales y urbanas) y permiten la construcción de imágenes y universos culturales si no nuevos, al menos en combinaciones diferentes a las que está habituada la cultura pública. Es por eso que puede esperarse que habrán de incidir en la autorrepresentación de la identidad social. La puesta en sen- tido, desde la arqueología de las sociedades indígenas, consiste en la posibilidad de elaborar una crítica histórica. No se puede ignorar la densidad del proceso que desemboca en una ecología cognitiva cuyo resultado resultado final es de naturaleza perceptivo-simbólica y proviene de ajustes al medio logrados a través de la técnica estratificada (es decir, superpuesta funcional y productivamente) a lo largo de la historia. La sede de este proceso es la superposición de los paisajes culturales y tecnológicos, su depósito histórico y su imbricación contemporánea.

La problematización crítica de lo que está por fuera de los sitios arqueológicos pone en contraste aquéllo que ha solido ser la base de la práctica arqueológica: la contemplación exótica de la que suelen ser objeto. Ella no es ajena al ámbito académico y puede referirse tanto a los hechos como a los modelos. Contemplación añadida al consumo cultura de proyectos teóricos constituyen el nudo de la disrupción entre arqueología y sociedad, entre arqueología y demanda social de conocimiento. Asimismo, ella puede verse desde la perspectiva de la correlación entre producción científica y Estado.

Tomar a los restos arqueológicos como parte de los recursos culturales obliga a estudiar cómo el Estado se hace coextensivo, en la región, de una dialéctica particular: la del modelo étnico de $\mathrm{Na}$ ción con su énfasis en la cultura vernacular; frecuentemente manifiesto bajo la forma de expresiones nativistas, populistas, etc.; $\mathrm{y}$, el modelo cívico de Nación, que vuelve al indio un ciudadano abstracto reabsorbiendo las discontinuidades étnicas en la homogeneidad del Estado-Nación (cfr. Smith, 1990: 145). La producción arqueológica está en condiciones de poner en vigor una visibilidad oculta o alternativa, por detrás de la uniformidad lograda en virtud del control cultural.

\section{ARQUEOLOGÍA Y REFORMA SOCIAL}

La idea de reforma social afecta, en primer lugar, la evaluación de los modelos de sociedad, sea que mirando al pasado se adviertan formas sociales alternativas que impugnan las cotidianas (13),

(13) Cuando la escenografía de locales de venta de artesanías, comercios de distinto tipo, hoteles, oficinas de turismo, etc. recogen objetos arqueológicos, sus réplicas o sus versiones kistch ayudan a confrontar una visibilidad histórico-étnica con la visibilidad desarrollada por el modernismo de la posguerra del siglo XX. 
sea que recorrer el pasado objete el proceso histórico que ha conducido a la experiencia social actual (14) en segundo lugar, refuerza la conexión con las ciencias de la sociedad, puesto que sólo ellas se proponen la crítica y reformulación de su objeto -la ciencia natural se propone el dominio de la naturaleza y no su reforma (Bobbio, 1987: 9)- reedita la metáfora de los "constructores de sociedades", por la cual el estudio de la sociedad es instrumental-político y fundamentalmente transformador.

Ciertos aspectos de la arqueología convocan a una mediación entre la preocupación por la crítica social y la reforma misma de la sociedad. Ésta se halla en el seno mismo de la actitud de asumir que puede no existir una sola cultura legítima en un país que impone a su población una sola, homogénea y europea (15). El reconocimiento de una red social de sitio es ya una intención transformadora. Ella consiste en nexos concatenados que involucran actores sociales en distintas dimensiones de compromiso con los sitios arqueológicos y con su universo documental. Empieza con los vecinos cuyas viviendas están próximos a ellos, continúa con la comunidad local (con su interacción local y su sistema de gobierno), abarca niveles jurisdiccionales y de comunicación más amplios, convoca al público en general y a las distintas formas de comunidad académica nacionales e internacionales. A lo largo de sus conexiones visibles y tácitas y en sus numerosas modalidades de movimiento interior, ella consiste en pura comunicación, en una escala más o menos amplificada de símbolos y de valores.

La acción transformadora realiza sus objetivos en gestiones públicas en lo educacional, en lo administrativo, en lo informacional, hasta dar nueva forma a la conciencia histórica (en sí y para sí, autónoma y crítica). En la arqueología de las sociedades indígenas, el imaginario sobre el cambio histórico tiene una afinidad muy intensa con la

(14) Se pueden pensar otras modalidades de vinculación con el ambiente: por ejemplo, las economías indígenas eran apropiativas pero no predadoras, sus agriculturas eran "orgánicas" y sus relaciones sociales eran solidarias y basadas en la reciprocidad, así que su impacto sobre el medio enseña otras formas éticas de "estar en la naturaleza".

(15) Una parte importante de este punto tiene que ver con el análisis de las causas históricas que han llevado a la situación actual de los indígenas en la Argentina, arrinconados en áreas periféricas no sujetas a disputa por la propiedad de lotes, desalojados de tierras de hábitat tradicional para la construcción de represas, asimiladas al proletariado urbano o a las clases más pobres de la sociedad. historia de la tecnología, hasta punto tal que ella puede considerarse una "ciencia de la tecnología" si se espera "...trascender los límites de la descripción material" (Hayden y Kamminga, 1979: 2). Este vínculo puede devenir en una traba para la lógica comunicativa y para la necesidad de trascender públicamente. Los cambios tecnológicos ofrecen una escala de la Prehistoria porque ellos aportan organizaciones temporales eficaces desde el punto de vista sistemático y en un tramo muy extenso de la misma proveen el único criterio posible para escindir etapas de desarrollo social (por ejemplo, los tiempos remotos que van desde unos dos millones de años en la Prehistoria del Viejo Mundo y desde, por lo menos, veinticinco mil en el Nuevo). Muchos cambios tecnológicos son desconcertantes o casi irrisorios para la percepción tecnológica del público general (16). Las formas repetidas en piedra, cerámica, metal, hueso, etc. indican la existencia de esquemas clasificatorios equivalentes a reglas sociales que gobiernan la gramática del diseño tecnológico. Cambios y gramática del diseño aproximan la historia y la ciencia de la tecnología prehistórica a la taxonomía cultural.

Al clasificar objetos, gentes, usos y conjuntos de variabilidad espacial y temporal no puede evitarse caer en la esquematización histórica (generalmente en forma de períodos y etapas) y en la sobresimplificación de los procesos de adaptación, de organización territorial, de intercambios materiales y simbólicos, etc. La historia que resulta carece de "detalles"; es una historia "sin sujetos". Simultáneamente, el pasaje a otros materiales significantes como el del cine, por ejemplo, conlleva el fantasma de la "malversación" del saber: para unos deviene en un saber sobre las cosas exóticas, para otros se transforma en descripciones locales o insuficientes del orden social antiguo.

Si bien la práctica normal de la arqueología indígena se afirma sobre la producción de textos, su objeto es -básicamente- de carácter visual. ¿Qué

(16) Es lo que ocurre en el nivel de formatización reconocible de los objetos líticos (especialmente) como cuchillos, raspadores, raederas, etc., de su función (que suele presentarse en un espectro que va desde la variación multifuncional a la alta especialización instrumental), en la presencia o no de enmangamiento (el cual prolonga el cuerpo de la pieza y explota sus posibilidades mecánicas, etc.), en la manufactura de piezas líticas (cuya variación comprende percusión simple, percusión para lascas pre-programadas, presión, pulido, etc.). Todos estos casos escapan a lo que el público puede reconocer sin una preparación previa y profesional.

T. P., 54, n. ${ }^{\circ} 2,1997$ 
clase de cosas-objetos llegaban a tener existencia social? ¿ Una vez que la conseguían cómo circulaban? ¿Cómo devenían familiares y cotidianas? En cierta forma la arqueología indígena no sólo tiene que ver con objetos visuales sino, también, con su inserción cotidiana, con la percepción y valoración del diseño "en uso". La memoria se organiza de tal modo que, al mismo tiempo que se recupera la habilidad asociada al diseño, se reconoce la etnicidad del mundo indio.

El reconocimiento de la identidad étnica realiza categorías sociales en el interior de un código: lo que hace de los rasgos étnicos, no la mera suma de diferencias objetivas sino la combinación de aquéllas que se consideran significativas $\mathrm{y}$, por consiguiente, adscriben, a los actores indígenas en la historia natural (cfr. Barth, 1976). Las diferencias se advierten -desde la arqueologíaen la frontera tecnológica, simbólica, imaginal, etc. (17). El plano de reconocimiento que ofrece la memoria étnica constituye un espacio transformador en la esfera de los valores con que se adscribe a la historia indígena en la historia regional y nacional. Los artefactos, grafismos, entierros y restos de todo tipo tienen el lugar de los sistemas de significación (Layton, 1989: 5). Los distintos actores sociales comprometidos en la red de sitio reelaboran ese pasado no sólo en términos de sus interpretaciones e ideologías sino también de los sucesivos bloques históricos de representación y de construcción de valores entrecruzados, superpuestos e intrincados en el transcurso de la vida "nacional".

Así, pues, subjetividad y política confluyen para demarcar la historia de la sociedad india. La teoría y los métodos de la arqueología están cruzados por los planos políticos de la sociedad argentina y por el lugar asignado a las sociedades indígenas en ellos. La arqueología de estas sociedades transita un género de producción literaria cuyo estilo de relato prioriza la cronología lineal. Es correlato de un gesto cultural argentino que recupera el orden social de la Patria Vieja (colonial, independentista y pre-inmigratoria). Es resultado tanto de la diferenciación romántica del ethnos como de la oposición al proyecto de la universalidad positivista, nacido en los 80 del siglo pasado. Reedita la cuestión de pertenecer o no a

(17) Reconocimiento de la etnicidad no quiere decir que un repertorio tecnológico, simbólico, etc. sea equivalente a una sociedad, a un grupo social, una comunidad, sino reconocimiento por contraste antropológico de una alteridad cultural productora. sociedades con o sin Estado (Herzefeld, 1987: 86), a sociedades homogéneas y tribales o a sociedades diferenciadas y "complejas".

La mezcla de estas perspectivas (la búsqueda "nacionalista" de una identidad para el país, a la que la sociedad indígena aportaría los elementos más distintivos y "legítimos" de su cultura; la insistencia en el tema de la objetividad reconstruccionista) incide en la metáfora del tratamiento escolar. Si, por un lado, se evoca a las sociedades indias en algún punto de la historia nacional (preferentemente bajo la figura de pobladores autóctonos y primordiales) y como una taxonomía de comunidades, economías, organización social y costumbres; por otro se enfatiza la desconexión de la sociedad argentina de este siglo con ellas. La idea de que el pasado indio es un pasado objetivamente superado tiene poder social. Esta circunstancia requiere una etnografía de lo que está afuera (Leone, 1987) de los sitios arqueológicos y una etnografía de la sociedad argentina misma (18).

El juicio de realidad, es decir, el imaginario desenvuelto alrededor de las sociedades indígenas, es inseparable del juicio axiológico que posiciona a las mismas en el ámbito de una historia definitivamente superada. El análisis de estas prescripciones consiste en una crítica cultural orientada a examinar un modelo de cultura -el que la sociedad argentina tiene para sí- por oposición a un contra-modelo que generalmente se asume como la tribalidad separada de la Nación. No se trata de volver a una etapa de tecnología y de organización social que sería impotente en este siglo sino en establecer el proceso por el cual la Argentina fue des-indianizada y, sobre todo, sus consecuencias regionales en torno de la apropiación del territorio.

Provisoriamente, y en situación cultural productiva, la arqueología indígena queda comprometida con los "recursos culturales". Allí también es necesario ejercer la crítica cultural del emergente de una autoridad etnográfica (Clifford, 1991) (19). Ella suele asumir la suma del conoci-

(18) Etnografía de lo que está afuera equivale a una descripción pormenorizada y totalizando a la sociedad local y nacional, a una interpretación de sus procesos histórico-sociales y a un diagnóstico de sus centros de significación principales así como de sus líneas de conflicto. En ese proceso el pasado indio es un estrato de sentido más o menos ligado al imaginario que la sociedad actual tiene sobre sí misma.

(19) La idea de autoridad etnográfica es complementaria de la de silencio etnográfico. El antropólogo deviene autor y 
miento sobre los objetos arqueológicos, sobre su filiación y antigüedad y consolida una "versión" sobre ese pasado. Tiene dos formas distintas pero complementarias; una institucional y con competencias definidas, la otra se halla fuera de ese marco y posee un curso de acción mucho más difuso. La primera encarna en la producción sistemática de los expertos académicos y se expresa orgánicamente en medios de comunicación científicos. La segunda es ejercida por otro tipo de experto: el coleccionista.

Su autoridad, bajo la forma de palabra o voz dotada de saber y monopólica, posibilita la acción apropiadora de objetos arqueológicos y de la información etnográfica e histórica relacionada con ellos. Los primeros los retienen en los museos, institutos y universidades por tiempos más o menos largos para su análisis y muestra. Esta retención es favorecida por el financiamiento institucional y por los géneros de literatura académica que consagran un solo estilo de voz experta. Los otros son apropiadores y conocedores ad hoc $\mathrm{y}$-de acuerdo con la envergadura de los objetos arqueológicosligados o no al mercado de antigüedades.

En el ámbito de los receptores se encuentran el público y la comunidad. No lo son solamente por su ubicación sino, especialmente, por su vínculo con las formas de autoridad etnográfica señaladas. El público está constituido por un conjunto abstracto, anónimo, siempre en modificación respecto a modas e intereses y en situación de disponibilidad para los media de comunicación. La comunidad pertenece a la red social de sitio arqueológico, está comprometida con su vecindad y con cierto grado de percepción familiar de las ergologías indígenas que potencialmente aparecen en los yacimientos, los cuales - a la vez- suelen estar en las inmediaciones de sus viviendas o de sus lugares de trabajo y paseo. El público tiende a ser recortado en el plano de lo nacional y la comunidad en el de lo local, que en la Argentina es el lugar del Interior (20).

autoridad sobre lo que observa en la situación de campo. Esa autoridad es casi inapelable por cuanto él ha estado allí, en el lugar y tiempo precisos como para ser testigo y observador participante (cfr. Geertz, 1990). Los arqueólogos se vuelven una autoridad análoga; no solamente porque hacen una suerte de etnografía a partir del registro arqueológico sino porque son, en cierta forma, insustituibles: la experiencia de excavar y registrar los hace testigos únicos y privilegiados de los observables que recuperan para la posteridad. El silencio etnográfico aparece cuando el antropólogo (arqueólogo) dẹcide qué escribirá y qué no, qué comunicará y qué no.

(20) La Argentina es un país vertebrado históricamente en torno a la escisión capital/interior. La primera (junto con la am-
El coleccionismo disputa a los expertos la apropiación de los objetos y la legitimidad de la experiencia y de conocimiento. Los coleccionistas están en las redes orgánicas de la pertenencia a la comunidad local y, generalmente, no hacen de las colecciones "cosas públicas", cosas "mostrables". Los expertos institucionales, por el contrario, necesitan y deben hacer públicas las estrategias de investigación y la producción académica aunque, frecuentemente, pasan por alto la conexión funcional con la comunidad y el público.

Experiencias sistemáticas y coleccionismo engendran culturas diferentes. Una argumenta desde la ideología de la recuperación exacta, la otra se articula en torno de la del valor (estético, histórico, de mercado, etc.). A veces se combinan en la instancia del consumo de industria cultural (literatura, artículos periodísticos, films, etc.) dirigida al público. Los recursos culturales arqueológicos están, pues, plenos de riqueza simbólica. No la pierden cuando cambian de material significante (de los textos al film, a la muestra gráfica, a la inforgrafía, a la exposición de objetos en museos o en su arrinconamiento doméstico).

La ciencia organiza universos de discurso nuevos cada vez que reorganiza o cambia -y lo hace periódicamente- modelos y teorías. Mientras los niveles de los coleccionistas y del público se encuentran fundados en la circulación de discursos que suelen ser estables y -básicamente- valorativos.

La intención y la posibilidad de acción reformista comienza en la dimensión de cuán eficaz es la inserción en la conciencia pública (y en sus distintos nexos de red social) de nuevas imágenes y nuevas formas de evaluación de las sociedades indígenas. En este punto éstas se vuelven un instrumental político para efectuar una crítica del modelo cultural hegemónico y para comprender que el bloque histórico que llamamos Nación resulta de un orden que eliminó a esas sociedades, no sólo como entidades jurídico-políticas porque se les oponían en el Desierto sino que también las anuló como sujeto histórico diferenciado y no única-

plia región litoral-pampeana) representa la conexión europea, tanto en su cultura pública cuanto en la idiosincrasia de su imaginario colectivo. Desde allí emanó el proyecto nacional que hizo de la Argentina una formación económica dependiente de Europa primero y de los EE.UU. después. El Interior está constituido a expensas de las provincias alejadas de la cuenca atlántica y la Patagonia. En la historia oficial, y el imaginario colectivo aprendido a partir de ella, el Interior representa la barbarie y la naturaleza indómita del "país real". 
mente a las que derrotó en el siglo XIX sino a las que las precedieron (aunque en la dimensión simbólica). No es indiferente, entonces, que por esa época, simultáneamente surgiera la arqueología científica (convirtiendo a las antigüedades aborígenes en objetos para investigar y para acumular en el Museo) y al coleccionismo privado en actividad si no lucrativa por lo menos prestigiosa (21).

El corpus documental recuperado por la práctica arqueológica (sistemática o de coleccionismo) convoca sectores sociales de distinto nivel y de compromiso heterogéneo en intensidad y adecuación, volviendo esos recursos culturales campo de apropiación y competencia. El destino académico y social de los mismos es - por añadidura- instrumental y político. La acción sobre el imaginario público y su escala axiológica trasciende las finalidades educativas y comunicacionales. Posee ramificaciones cruciales sobre la conciencia histórica disparándola hacia el pasado, pero también hacia el futuro: el tratamiento que se ha dado y se da a las minorías indígenas es paradigmático del debate sobre las libertades políticas, sociales, económicas en la Argentina.

La estrategia especializada de investigación necesita encontrar lenguajes plurivalentes, superar su equivalencia con la historia de la tecnología y con la búsqueda de una sociedad indígena eternamente adecuada ("ajustada" o "adaptada") por la homeostasis ecológica. Un esfuerzo de esta naturaleza estaría dirigido a trazar una historia india dotada de sujeto.

\section{BIBLIOGRAFÍA}

Alcina Franch, J. (1989): Arqueología antropológica. Akal. Madrid.

Austral, A.G. y Rocchietti, A.M. (1990): “Complejo de instalaciones indígenas en Sierra de Comechingones Meridional (Córdoba-Argentina). El caso Piedra del Aguila". Revista do CEPA. Facultades Integradas de

(21) Los argumentos expuestos no deben llevar a la conclusión de que estamos haciendo el elogio del coleccionismo. Estamos procurando analizar todos los costados de la relación arqueólogo ("expertos institucionales") y coleccionistas (en mayor o menor grado, con alto nivel de rigurosidad o con marcada improvisación, con interés por la ganancia o sin él), señalando que desde ambas partes se producen apropiaciones, especialmente si hacemos entrar en consideración que actualmente las comunidades aborígenes, sus representantes orgánicos o sus miembros aislados desempeñan un rol prácticamene nulo en este tema, aun en el ambiente académico. Esto último refleja el grado -bajo- de autoorganización y de reclamo de que ellos adolecen.
Santa Cruz do Sul (ASPESC) 17, 20, sept. Brasil: 371-385.

BARTH, F. (1976): Los grupos étnicos y sus fronteras. Fondo de Cultura Económica. México.

Boвbio, N. (1987): Teoría de las formas de gobierno en la historia del pensamiento político. Fondo de Cultura Económica. México.

Bonfil Batalla, G. (1991): "12 de octubre: a propósito del Quinto". En A. Colombres (coord.): 1492-1992: a 500 años del choque de dos mundos. Balance y perspectiva. Ediciones del Sol. Buenos Aires.

Borel, J. (1981): 'L' explication dans 1 'argumentation. Approache sociologique". Langue Française, 80: 2033.

Bunge, M. (1994): Sociología de la Ciencia. Ed. Siglo XX. Buenos Aires.

CASTORIADIS, C. (1990): La institución imaginaria de la sociedad. Tusquet. Buenos Aires.

Clifford, J. (1991): "Sobre la autoridad etnográfica". En C. Reynoso (comp.): El surgimiento de la antropología post-moderna. Gedisa. Buenos Aires: 141-170.

Colombres, A. (1988): La hora del bárbaro. Ediciones del Sol. Buenos Aires.

CRIAdo BoAdo, F. (1993): "Visibilidad e interpretación del registro arqueológico". Trabajos de Prehistoria. 50: $39-56$

FANFANI, A. (1991): "Las ciencias sociales en la Universidad”. En Espacios de Crítica y Producción. Facultad de Filosofía y Letras. Universidad de Buenos Aires. Nov.-dic: 7-13.

Feyerabend, P. (1990): Adiós a la razón. Rei. Buenos Aires.

Foley, R. (1981): "A model of regional archaeological structures". Proceedings of the Prehistoric Society, 47: 1-17.

Foucault, M. (1981): As palavras e as cosas, uma arqueologia das Ciencias Humanas. M. Fontes. San Pablo.

García Canclini, N. (1991): "Consumo cultural en América Latina". En Espacios de Crítica y Producción. Facultad de Filosofía y Letras. Universidad de Buenos Aires. Nov.-Dic.: 75-81.

Geertz, C. (1990): El antropólogo como autor. Paidós. Buenos Aires.

GidDENs, A. (1987): Las nuevas reglas del método sociológico. Amorrurtu. Buenos Aires.

GLocK, A. (1985): "Traditional change in two archaeologies". American Antiquity, 50 (2): 464-477.

HABERMAS, J. (1971): Toward a natural society. Heinemann. Londres.

HAYDEN, B. y Kamminga, J. (1979): "An Introduction to Use-Wear". En B. Hayden (ed.): Lithic use wear analysis. Academic Press. N. York: 1-13.

HeRzEFELD, M. (1987): Anthropology through the looking glass. Cambridge University Press. Cambridge. 
Hodder, I. (1988): Interpretación en Arqueología. Crítica. Madrid.

LAYTON, R. (1989): "Introduction. Conflict in the archaeology of living traditions". En R. Layton (ed.): Conflict in the archaeology of living traditions. One World Archaeology, 8. U. Hyman. Londres: 1-41.

LEONE, M.P. (1987): “Toward a critical archaeology". Current Anthropology, 28 (3): 283-302

MANZINI, E. (1991): Vers une ecologie de l'environment artificiel. Centre Pompidou. Paris.

Mercier, P. (1986): La sociedad digital. Sudamericana. Buenos Aires.

Moles, A. (1991): "Pensar en línea o pensar en superficie”. En J. Costa y A. Moles (comps.): Imagen didáctica. CEAC. Barcelona.

PATRICK, L.E. (1983): "Is there an archaeological record?". En M.B. Schiffer (ed.): Advances in Archaeological Method and Theory, 8. Academic Press. New York: 27-62.

PATtERSON, Th. (1989): "La historia y las arqueologías post-procesuales". Boletín de Antropología Americana, 20, dic.: 5-18.
Prigogine, Y. y Stengers, I. (1983): La nueva alianza. La metamorfosis de la ciencia. Alianza. Madrid.

RocChIETTI, A.M. (1991): "Arte étnico, antropología de lo visual y montaje arqueológico". Boletín del Centro, 2, sept. La Plata: 160-167.

Shumway, N. (1992): La invención de la Argentina. Historia de una idea. Emecé. Buenos Aires.

SMith, A. (1990): The ethnic origins of Nations. B. Blackwell. N. York.

Sullivan, A. (1988): "Current Issues in Regional archaeology". En Symposium Proceedings Tool to Manage the Past: Research Priorities for Cultural Resources Management in the Southwest. Department of Agriculture. Forest Service. EE.UU.: 81-89.

VICENT, J. (1991): “Arqueología y Filosofía: la teoría crítica". Trabajos de Prehistoria, 48: 29-36.

Wolf, E. (1982): Europa y la gente sin historia. Fondo de Cultura Económica. México.

ZiMMERMAN, L. (1989): "Made radical by my own: an archaeologist learns to accept reburial". En R. Layton (ed.): Conflict in the Archaeology of living traditions. Unwin Hyman. Boston: 60-67. 